\title{
NUEVAS PERSPECTIVAS SOBRE LA MUTACIÓN DEL SISTEMA DE CONTROL DE CONSTITUCIONALIDAD EN ARGENTINA
}

\section{NEW PERSPECTIVES ABOUT MUTATION OF CONSTITUTIONAL REVIEW SYSTEM IN ARGENTINA}

RESUMEN:

La constitución argentina de 1853 no incluye reglas sobre el ejercicio del control de constitucionalidad; a partir de cuya ausencia la Corte Suprema de Justicia de la Nación se adjudica una autoatribución monopólica para el diseño del sistema y su ejercicio; creando las reglas del tradicional sistema de control de constitucionalidad federal argentino. No obstante, frente a este clásico sistema, desde hace algunos años la propia Corte Suprema de Justicia de la Nación propone una flexibilización del diseño original y una mutación sobre sus notas caracterizantes con vocación hacia la hibridación del sistema. Este trabajo propone la identificación y descripción de dicho proceso jurisprudencial mutativo sobre una de las notas caracterizantes del tradicional sistema de control de constitucionalidad argentino: el monopolio judicial del control; y explorar desde allí la injerencia del órgano ejecutivo en materia de control de constitucionalidad sobre normas presuntamente inconstitucionales.

\section{ABSTRACT}

1853 Argentine constitution does not include rules about constitutional review; from whose absence the National Supreme Court of Justice takes on the self attributed monopoly of the construction of its classics rules.

However, against this classic review system, the National Supreme Court of Justice has proposed a flexibilization of the original design and a mutation on its characteres in order to promote an hybridization of the system. 
On this context, this paper proposes the identification and description of this mutative jurisprudential process on one of the most important character of Argentine constitutional review classic system -the judicial monopoly of control- in order to explore the executive branch ability for constitutional review over invalid on its face or facial challanges.

PALABRAS CLAVE: Control de constitucionalidad - autoatribución monopólica - mutación e hibridación- administración pública/función ejecutiva - normas presuntamente inconstitucionales.

KEY WORDS: Constitutionality control - self-attribution monopolistic - mutation and hybridization - public administration / function executive - allegedly unconstitutional rules.

\section{Consideraciones Introductorias}

En 1887 Argentina inaugura el proceso gestacional de su sistema de control de constitucionalidad a través de los fallos "Sojo, Eduardo c/ Cámara de Diputados de la Nación" (1987) y "Municipalidad de la Capital c/ Elortondo" (1888); siguiendo los principios medulares que el fallo de la Supreme Court Norteamérica "Marbury vs. Madison" (1803) delineara sobre la supremacía constitucional y la competencia de la magistratura para el ejercicio de su control:

"Hay sólo dos alternativas demasiado claras para ser discutidas: o la Constitución controla cualquier ley contraria a aquella, o la legislatura puede alterar la Constitución mediante una ley ordinaria. Entre tales alternativas no hay términos medios: o la Constitución es la ley suprema, inalterable por medios ordinarios, o se encuentra al mismo nivel que las leyes, $y$, por lo pronto, como cualquiera de ellas, puede reformarse o dejarse sin efecto siempre que al Congreso le plazca (William Marbury v. James Madison, february term, 1803."

La redacción original de la constitución argentina de 1853 no incorpora reglas para el ejercicio del control, omitiendo toda prescripción expresa sobre el tema; cuestión parcialmente subsanada con la reforma constitucional de 1994 a través de la última parte del primer párrafo del artículo 43.

A partir de la ausencia de esta codificación dentro del texto constitucional, la magistratura argentina, encabezada por la Corte Suprema de Justicia de la Nación (CSJN en adelante), asume la tarea de completar jurisprudencialmente el olvido del constituyente, y a través de sus sentencias fue delineando sus contornos característicos, adjudicándose -en defecto- una autoatribución monopólica tanto para el diseño del sistema de control como para su ejercicio; gestando a través de la práctica sentencial las reglas del tradicional sistema de control de constitucionalidad argentino.

En el marco de dicho proceso de formulación pretoriana, se han ido definiendo los caracteres de lo que se identifica como "sistema tradicional o clásico" de control de constitucionalidad federal en nuestro país: judicial, difuso, en el marco de una causa o controversia, a requerimiento de parte, indirecto o incidental y con efecto restringido o inter partes; fundado en la presunción de constitucionalidad de los actos estatales; esto es, el proceso genealógico del sistema de control argentino adscripto a los fundamentos y caracteres del modelo norteamericano.

No obstante, frente a este clásico sistema de control instaurado en Argentina, desde hace algunos años la propia CSJN ha habilitado el debate sobre su rigidez y alcances, 
derivando en una consecuente flexibilización del diseño original y una mutación sobre sus notas caracterizantes, con vocación hacia una hibridación (Pegoraro, Lucio 2002). Así, cada uno de los caracteres definitorios de este tradicional sistema se han ido cuestionando

“(...) y las paulatinas y graduales interpretaciones que la Corte Suprema de Justicia de la Nación ha ido brindando en el ejercicio de su rol de último y definitivo guardián en la exégesis de la Carta Magna, parecen haber dado cierta elasticidad al modelo original" (Estevarena, Florencia, 2006).

En tales términos, es posible evidenciar un proceso de elastización sobre los caracteres del modelo tradicional de control a través de distintos fallos de la CSJN, dando señales de un proceso mutativo sobre sus caracteres; y manifestando una hibridación (Pegoraro, Lucio 2002) hacia sistemas de control foráneos, trascendiendo su histórico legado norteamericano que lo ubicaba en nítida contraposición al verfassungsgerichtsbarkeit Kelseniano -inaugurado en la constitución austriaca de 1920-; trayendo como consecuencia que el sistema de control de constitucionalidad argentino haya dejado de ser un sistema puramente adscripto al modelo norteamericano, dirigiéndose hacia un modelo con perfiles mixturados (Bazán, Victor 2010 y Ferreyra, Gustavo 2004).

Este trabajo se proyecta sobre un objetivo central, la identificación y descripción del proceso jurisprudencial mutativo sobre una de las notas caracterizantes del tradicional sistema de control de constitucionalidad argentino: el monopolio judicial del control; y explorar desde allí la posibilidad de un control de constitucionalidad por parte de la Administración Pública, que en cumplimiento de su deber de actuación legal debe dar vigencia a las prescripciones constitucionales no aplicando aquellas normas presuntamente inconstitucionales.

Esta nueva modulación pretoriana resulta en conformidad a lo ordenando por la Corte Interamericana -caso GELMAN (CIDH)-, quien ha afirmado ya la obligatoriedad de todas las autoridades públicas de llevar adelante un control de convencionalidad en el marco de sus competencias, lo cual lleva ínsito la potestad de realizar un control de constitucionalidad.

\section{1- El control de constitucionalidad y la deliberada omisión del constituyente argentino}

El texto original de la Constitución argentina de 1853 no define expresamente un sistema de control de constitucionalidad (Dalla Via Alberto, 1997) siguiendo la tradición norteamericana:

"Al igual que en Argentina, en Norteamérica el control de constitucionalidad tiene un proceso genealógico pretoriano: no surge de la letra de la Constitución americana, pero fue bajo el paraguas de estas ideas y circunstancias que tuvo lugar la célebre decisión recaída en el caso "Marbury vs. Madison" (1803), en el cual se materializó la idea sobre el control jurisdiccional de la constitucionalidad de las leyes (judicial review) (Highton Elena I., 2011, p. 114)".

"El control de constitucionalidad de las leyes no fue diseñado expresamente en el texto constitucional argentino de 1853. A semejanza del proceso que se vis/umbró en el derecho constitucional norteamericano, la fuente de la que provienen los elementos principales que configura los requisitos para que procesa el control de constitucionalidad y el enmarcamiento de su radio de acción se han gestado primordialmente en sede judicial" (Ferreyra, Gustavo 2004, p. 19).

En este contexto, la omisión del constituyente no responde a un descuido involuntario, sino a una pretensión de conceder a la magistratura un margen de elasticidad interpretativa y creacional que le permita desarrollar con amplitud su función de árbitro com- 
ponedor y moderador, concediéndole así la función del sostenimiento de la supremacía constitucional, siguiendo los fundamentos de los propios constituyentes norteamericanos (García, José F. 2003):

"Es evidente que el lenguaje constitucional cumple un rol ideológico, ya que también a él le toca justificar una situación de poder (la enunciada en la constitución), y lograr asi obediencia social. No hay por ende, estilos constitucionales neutros ni ingenuos" (Sagues, Néstor 2007)

Así, en búsqueda de la formulación del diseño metodológico constitucional más apropiado, es decir con vocación de futuridad (Sagues, Néstor 2007), el constituyente argentino replicando las fuentes ideológicas norteamericanas de que [el poder judicial] será siempre el menos peligroso para los derechos políticos de la Constitución, porque su situación le permitirá estorbarlos o perjudicarlos en menor grado que los otros poderes (...) [y] que el departamento judicial es, sin comparación, el más débil de los tres departamentos del poder (El Federalista $N^{\circ} 78,1787$ ), resolvió no enclaustrar en una norma la potestad de control que entendió implícita del órgano judicial; concediéndole así un amplio margen de elasticidad.

Así, nuestra constitución, extraída del modelo norteamericano, encuentra justificación y sustento en las mismas fuentes que aquel, por lo que la razón de esta omisión constitucional debe rastrearse en los escritos del Federalista, y cuya edición № 78 ofrece una justificación para el monopolio judicial del control de constitucionalidad:

“ (...) La interpretación de las leyes es propia y peculiarmente de la incumbencia de los tribunales. Una Constitución es de hecho una ley fundamental y asi debe ser considerada por los jueces. A ellos pertenece, por lo tanto, determinar su significado, así como el de cualquier ley que provenga del cuerpo legislativo. Y si ocurriere que entre las dos hay una discrepancia, debe preferirse, como es natural, aquella que posee fuerza obligatoria y validez superiores; en otras palabras, debe preferirse la Constitución a la ley ordinaria, la intención del pueblo a la intención de sus mandatario." (El Federalista N 78, 1787).

La ausencia de una codificación expresa sobre el control de constitucionalidad dentro del plexo de la carta magna argentina de 1853, trajo consigo que la judicatura asumiera como suya no sólo dicha actividad de control, sino también la prerrogativa del diseño de dicho sistema replicando las notas caracterizantes del modelo norteamericano. Así, Argentina ha seguido en el ámbito federal ${ }^{2}$ el esquema norteamericano originario (Bianchi, Alberto 2002), cuya adhesión la propia CSJN ha ratificado al expresar:

"El sistema de gobierno que nos rige no es una creación nuestra. Lo hemos encontrado en acción, probado por largos años de experiencia y nos lo hemos apropiado. Y se ha dicho con razón que una de las grandes ventajas de esta adopción ha sido encontrar formado un vasto cuerpo de doctrina, una práctica y una jurisprudencia que ilustran y completan las reglas fundamentales y que podemos y debemos utilizar, en todo aquello que no hayamos querido alterar por disposiciones peculiares" (De la Torre, Lino, 1877Fallos: 19:231)

"Nuestro sistema constitucional tiene su fuente originaria en la Constitución de los Estados Unidos de América -es decir, una constitución rígida que adopta el principio del constitucionalismo liberal clásico de la división de poderes- y reposa en la independencia de un Poder Legislativo, un Poder Ejecutivo presidencial y un Poder Judicial que ejerce el control de constitucionalidad, (V. Dreams, 1995, Fallos 318:1154).

Como consecuencia de su filiación norteamericana, el sistema argentino de control de

2 La diferencia entre el sistema de control de constitucionalidad del ámbito federal en relación a las provincias se acredita a través de modulaciones particulares en los textos y en la práctica local que promueven un distanciamiento del modelo puro norteamericano, tales como la que proponen las Constituciones de Chubut (arts. 175 y 179), entre ríos (art. 167), Formosa (art. 170 y 174), La Pampa (art. 97 y 101), Mendoza)(art. 144), Catamarca (art. 203) Río Negro, Córdoba (art. 165), ciudad autónoma Buenos Aires (art. 113), Santiago del Estero (art. 194), Neuquén (art. 30), etc. 
constitucionalidad federal ha conservado las notas características fundantes de dicho modelo foráneo, traducido en un poder judicial custodio y garante de la constitución que realiza de forma continua una tarea fiscalizadora de la adecuación de las normas y los actos estatales al texto constitucional en cada uno de los niveles de competencia judicial (judicial review); cualquiera sea el grado del magistrado actuante, y ante el planteo efectuado en un caso concreto o controversia donde sea puesta en duda la coherencia de dicha norma o acto, y para cuya resolución sea necesario resolver la impugnación contra ella, extendiendo los resultados de dicha sentencia sólo a las partes involucradas (Dalla Via, 1997; Bianchi, 2002; Haro, 2003; y Amaya, 2012).

De allí, que resulta posible resumir las características del sistema de control argentino como judicial, difuso, en el marco de una causa o controversia, a requerimiento de parte, indirecto o incidental y con efecto restringido o inter partes; fundado en la presunción de constitucionalidad de los actos estatales, conocido como regla de legalidad que se conservará mientras un magistrado no determine lo contrario y de donde deriva el control como "remedio de gravedad y ultima ratio".

\section{2- El proceso mutativo del control en Argentina}

Durante mucho tiempo este modelo resultó fortalecido por la CSJN, sin embargo, fue este mismo órgano el encargado de ir elastizando la rígida concepción original. Así, en los últimos años, distintos fallos inauguraron el proceso de discusión sobre la rigidez de dicho sistema de control normativo, permitiendo nuevas modulaciones sobre su alcance y ejercicio.

Conforme ello, el proceso de mutación -hibridación- del control de constitucionalidad se manifiesta en los siguientes extremos:

a) El requerimiento de pedido de parte muta hacia un control constitucional de oficio, consolidado en virtud de los fallos "Banca Comercial de Finanzas" y "Mill de Pereyra.

Desde su instalación en 1863 hasta 1941 la CSJN no manifestó reglas concretas sobre el tema; recién en 1941, en el fallo "Los Lagos SA Ganadera c/ Gobierno Nacional" estableció como regla general que el control no podía realizarse de oficio, salvo cuando se tratara de mantener su independencia como poder o cuando era necesario preservar la integridad del poder judicial.

En 1983, se modifica la posición tradicional a través de las disidencias de los Ministros Bellucio y Fayt en el fallo "Juzgado de Instrucción $N^{\circ} 50$ de Rosario", lo que se reiteraría nuevamente a través de Boggiano en "Bco. Bs.As. Building Society s/ quiebra", de 1998; y "Ricci, Oscar Francisco Augusto c/ Autolatina Argentina S.A. y otro s/ accidente - ley 9688, del mismo año.

El 27 de septiembre de 2001 en el fallo "Mill de Pereyra, Rita A. y otros c. Provincia de Corrientes", la Corte se pronuncia habilitando el control de oficio que luego sería confirmado finalmente en Banco Comercial Finanzas S.A. (en liquidación Banco Central de la República Argentina) s/ quiebra (2003).

b) La aparición de un control de tipo preventivo y abstracto de constitucionalidad, encubierto por la CSJN a través del dictado de acordadas y la creación pretoriana de la acción declarativa de inconstitucionalidad (enancada en el art. 322 del CPCCN), e incluso por las sentencias que declaran la inconstitucionalidad sobreviniente (Villarreal, Mario c/ PEN-PLN y Máxima AFJP s/amparo, 2014) y que vienen a modificar las previsiones históricas sobre la temporalidad del control (Itzcovich, Mabel c/ ANSeS s/ reajustes varios, 2005) debilitando los caracteres tradicionales del sistema argentino. 
c) El efecto inter partes de la declaración de inconstitucionalidad ha resultado tambien superado a través de las denominadas sentencias constitucionales atípicas (Dalla Vía, Alberto $R$., 2009), de la amplia legitimación otorgada a partir de la reforma constitucional de 1994 en los artículos 42 y 43 y los derechos colectivos y la admisión de la acción de clase ("Halabi, Ernesto c/ PEN - ley 25.783 - dto. 1563/04 s/ amparo ley 16.986", 2004) y la idea del stares decisis vertical (Buteler, Alfonso 2012. p.14) y la vinculatoriedad de las sentencias del CSJN hacia los tribunales inferiores y el efecto erga omnes de sus sentencias ("Pedraza, Héctor Hugo c/ ANSES s/ Acción de amparo" 2014) (Sagüés, Néstor P. 2006).

Así, frente al ejercicio del control de constitucionalidad en las causas traídas a su conocimiento, la magistratura nacional discurría históricamente entre 2 posibilidades sentenciales: pronunciamientos estimatorios o desestimatorios, según acogiera o no la pretensión de declaración de inconstitucionalidad respectivamente, cuyos efectos se dirigían a los sujetos involucrados en la relación jurídica objeto del pronunciamiento, esto es, el tradicional efecto inter partes propio del esquema clásico denominado sentencias típicas. (Sagüés, Néstor P. 2006)

En el devenir de su desarrollo, la CSJN fue elastizando dicha modulación clásica por considerarla insuficiente frente a los reclamos que involucraban intereses de un universo mayor a los sujetos pretensores, de manera que seguir resolviendo entre las posibilidades antes identificadas no satisfacía el objeto ni los intereses en pugna: esto adquirió el tenor de sentencias o pronunciamientos atípicos por resultar diferentes a los modos en los que tradicionalmente la magistratura venía resolviendo. En estos casos, el carácter sobresaliente representa una extensión de los efectos del pronunciamiento a personas ajenas al proceso en cuestión.

d) Finalmente, la nota tipificante de control exclusivamente judicial es extendida en virtud del reconocimiento de una nueva categoría normativa, la de las leyes presuntamente inconstitucionales que viene a revertir no sólo la presunción de legalidad de los actos estatales sino el monopolio del ejercicio del control, ampliando los sujetos a cargo del control. Así, la CSJN a través de algunos fallos extiende la versión clásica del control de constitucionalidad a una nueva eventualidad, la del control de las leyes por órganos de carácter administrativo; asistiéndoles a estos últimos la posibilidad de no aplicar aquellas normas denominadas de presunta inconstitucionalidad.

Este trabajo se sitúa a partir del análisis del fallo Hooft, Pedro Cornelio Federico c/ Buenos Aires, Provincia de s/ acción declarativa de inconstitucionalidad del años 2003, seguido luego por los fallos Mantecón Valdés Julio c/ Estado Nacional. R. № 13/IX/04 y Reyes Aguilera, Daniela C/ Estado Nacional R. 350. XLI. 04/09/2007 que luego analizaremos en profundidad.

Esta nueva modulación pretoriana resulta en conformidad de lo ordenando por la Corte Interamericana (CIDH) (Caso Gelman Vs. Uruguay, 2011), quien ha afirmado ya la obligatoriedad de todas las autoridades públicas de llevar adelante un control de convencionalidad en el marco de sus competencias, lo cual llevaría ínsito la potestad de realizar un control de constitucionalidad (Hitters, Juan C. 2013).

Tal como este breve esquema de evolución jurisprudencial pretende señalar, el clásico sistema de control de constitucionalidad argentino resulta hoy de límites y márgenes más flexibles y elásticos, trayendo consigo un proceso de mutación hacia un nuevo sistema de control normativo.

\section{3- Sobre el monopolio del control judicial de constitucionalidad y las normas presunta- mente inconstitucionales.}


Desde sus primeros fallos, la CSJN ha sostenido su atribución para ejercer el control de constitucionalidad, posición que ha sido reiterada en innumerables oportunidades ${ }^{3}$, siendo responsable de la apropiación excluyente y monopólica de dicha tarea fiscalizadora; afirmado inicialmente en "Municipalidad de la Capital c. Elortondo (1888)":

"es elemental en nuestra organización constitucional, la atribución que tienen y el deber en que se hallan los tribunales de justicia, de examinar las leyes en los casos concretos que se traen a su decisión comparándolas con el texto de la constitución para averiguar si guardan o no conformidad con esta, y abstenerse de aplicarlas si las encuentra en oposición con ella, constituyendo esta atribución moderada, uno de los fines supremos y fundamentales del poder judicial nacional y una de la mayores garantías con que se ha entendido asegurar los derechos consignados en la constitución contra los abusos posibles en involuntarios de los poderes políticos".

Los actuales artículos 116 y 117 de la constitución ofrecen el sustento normativo que a grandes rasgos ampara esta prerrogativa judicial, completado por la ley № 27 a través de sus artículos 1, 2 y 3 con más la ley № 48 .

Sin embargo, a los efectos de este trabajo, no es necesario probar que el poder judicial es el órgano apto para realizar el control de constitucionalidad, sino acreditar que la función administrativa también puede llegar a hacerlo en el caso concreto, puesto que es igualmente inherente al ejercicio de sus funciones sometidas al plexo de la constitución nacional.

En tal sentido, la CSJN ofrece hoy nuevas precisiones conceptuales en el marco de sus sentencias tendientes a ampliar el control de constitucionalidad en una vocación hacia la hibridación. Esto encuentra un cauce de expresión en virtud de algunos fallos en los cuales la CSJN se expresa con un tenor bastante novedoso en referencia a las normas presuntamente inconstitucionales (proveniente de los fallos norteamericanos Brown v. Board of Education of Topeka, 1954 y Reno v. American Civil Liberties Union, 1997, denominado invalid on its face o facial challanges).

Todos los fallos que serán expuestos coinciden en el desarrollo de su plataforma fáctica, en tanto coinciden en la existencia de una clara, notoria y evidente violación de un derecho humano de esencial valor través de la aplicación de una ley o reglamento normativo evidentemente inconstitucional cuya gravedad hacer revertir el presupuesto apriorístico de legalidad en la cual se funda el estado de derecho (presunción iuris tantum).

En el primer caso "Hooft, Pedro Cornelio Federico c/ Buenos Aires, Provincia de s/ acción declarativa de inconstitucionalidad" (2003), Pedro Cornelio Hooft, ciudadano argentino naturalizado y titular de la fiscalía del departamento judicial de Mar del Plata con 35 años de servicio promueve demanda contra la Provincia de Buenos Aires, a fin de obtener que se declare la inconstitucionalidad o la inaplicabilidad para su caso, del art. 177 de la Ley Fundamental de dicha provincia, por ser contraria a la Constitución Nacional, en cuanto le cercena su derecho a ser Juez de cámara -o eventualmente de casación- al requerir para acceder a tal cargo, "haber nacido en territorio argentino o ser hijo de ciudadano nativo si hubiese nacido en país extranjero".

Ya al inicio de los considerandos, la CSJN manifiesta el vicio de la norma en cuestión en tanto se presenta afectada por una presunción de inconstitucionalidad que sólo podría ser remontada por la prueba concluyente de que existe un sustancial interés provincial que la justifique (Hooft, Consd.2, 2º́rrafo). Así, la presencia de uno de los motivos de

\footnotetext{
3 Ello, sin perjuicio de recordar que Argentina adoptó durante un corto periodo de tiempo un modelo de control de tenor político, más precisamente entre 1853 y 1860, durante el cual, el texto originario de 1853 (artículos 5, 64 inc. 28, y 103) atribuía al Congreso federal la competencia de controlar las constituciones provinciales antes de su promulgación, pudiendo reprobarlas si no estaban en conformidad con la constitución federal (Bidart Campos, 1996, p. 100), traduciéndose dicha atribución en una competencia fiscalizadora e interpretativa que resolvía posibles impugnaciones entre las cartas locales en relación al texto constitucional nacional, resolviendo por la preeminencia del segundo.
} 
discriminación categórica que los pactos internacionales prohíben hace pesar sobre la legislación que lo incluye una presunción, una sospecha de ilegitimidad, con desplazamiento de la carga de la prueba.

En el año 2006, a través del fallo "Gottschau, Evelyn Patrizia c/ Consejo de la Magistratura de la Ciudad Autónoma de Buenos Aires s/ amparo", la demandante, de nacionalidad alemana radicada en forma permanente en la República Argentina desde el año 1983 y abogada matriculada se presentó como postulante en el concurso para la Selección de Secretarios de Primera Instancia del Poder Judicial de la Ciudad de Buenos Aires, pero su solicitud fue denegada con invocación del art.10.1.4 del Reglamento de Concursos donde se exigía su calidad de argentina nativa o por naturalización al efecto. Recurrió contra la decisión, pero el plenario del Consejo de la Magistratura la confirmó. Accionó consecuentemente solicitando la inconstitucionalidad de dicha disposición.

Recordando lo resuelto en el caso Hooft, la CSJN esgrimió similares argumentos tendientes a sostener el evidente gravamen constitucional que dicha disposición normativa llevaba ínsita. A tal efecto refirió a la inversión de la carga probatoria, desestimando la regla general de presunción de validez de las leyes, a partir de la cual, quien desea su inaplicación debe probar su vicio.

En el año 2007, la CSJN al momento de expedirse en la causa "Reyes aguilera c/ estado nacional", resuelve con mayor profundidad en una temática referida a prestaciones universales del sistema de la seguridad social.

La actora, de nacionalidad boliviana, y que obtuvo su radicación en Argentina, padece de una incapacidad del ciento por ciento de carácter congénito, desde su nacimiento. En tales condiciones, ante la negativa de las autoridades administrativas a concederle la pensión por invalidez por no contar con la residencia mínima de 20 años requerida a tal efecto para los extranjeros, inicia acción de amparo invocando la inconstitucionalidad de este último precepto.

La CSJN, con las disidencias de los Dres. Lorenzetti y Highton de Nolazco, resuelve a favor de la reclamante, sin dar mayores precisiones dogmáticas sobre la cuestión, lo que sería profundizado a través del voto de los Dres. Petracchi y Argibay: esa contradicción directa con el texto constitucional obliga a considerar a la categorización realizada por el decreto como sospechosa de discriminación y hace pesar sobre dicha norma una presunción de inconstitucionalidad (...) (Reyes Aguilera Consid.11 del voto de Petracchi y Argibay).

La conceptualización final de la cuestión alcanza su punto de mayor expresión a través del fallo "Mantecón Valdes Julio c/ estado nacional - Corte Suprema de Justicia de la Nación - (concurso biblioteca) s/amparo" (2008) donde el tribunal vuelve a reiterar los extremos de este tipo de normas, insistiendo también en el carácter obligatorio de sus sentencias, y haciendo un llamado ya directo a la forma en que las normas con este vicio deben ser tratadas por los demás órganos del estado en el ejercicio de sus sendas funciones.

Julio Mantecón Valdés, de nacionalidad cubana acciona contra la resolución del 13 de septiembre de 2004 por la cual se desestimó su solicitud para participar en el concurso destinado a cubrir un cargo de auxiliar de la Biblioteca de la Corte Suprema de Justicia de la Nación y contra el art. 11 del Reglamento para la Justicia Nacional (Acordada CSJN del 17 de diciembre de 1952) que sirvió de fundamento a dicha desestimación, en razón de no cumplir con el recaudo de ser argentino.

La remisión a los precedentes mencionados es puesta de manifiesto en el dictamen del mismo procurador, quien atendiendo a las pretensiones del recurrente, se refiere al deber de la administración pública y los distintos órganos de aplicación de las normas 
de llevar a cabo un control ante casos de envergadura semejante, cuando las normas a aplicar lleven ínsitas una carga de discriminación so pretexto de ser reglamentarias y operatorias de un derecho constitucional más amplio:

Sin embargo, las citadas disposiciones [en referencia a las normativas reglamentarias que establecen los requisitos para el acceso al cargo en cuestión] no imponen tarea alguna al personal administrativo que pongan en juego los fines sustanciales que el test de "Hooft" menciona. Además, y ya con referencia a los medios aludidos en "Hooft" -y a la necesidad de aplicar alternativas menos gravosas, cuando existieran- (...) (Mantecón Valdés J. c/ Estado Nacional. № 13/IX/O4. Consid. VII) del dictamen del procurador Righi.) Lo que el procurador denomina TEST DE HOOFT, refiriéndose a este como mandato de la Corte a los demás órganos, hace referencia al deber de efectuar un control previo a la aplicación de toda norma infra constitucional, cuyo texto refiera al origen nacional como requisito para el acceso a un cargo público por concurso de idoneidad.

Atento ello, el test de Hooft hace las veces de un nuevo mecanismo de control de constitucionalidad que partiendo de una presunción de inconstitucionalidad de una norma, obliga a las distintos operadores del estado a tener a las normas así viciadas, pasibles de no ser utilizadas como fundamento legal de un acto administrativo.

\section{4- La supuesta imposibilidad de los órganos administrativos de efectuar el control constitucional:}

“(...) Cualesquiera sean las facultades que corresponde reconocer al poder administrador para dejar sin efecto actos contrarios a las leyes, no cabe -sin embargo-admitir que sea de su resorte el declarar la inconstitucionalidad de éstas. Ello asi porque aceptar semejante tesis importaría desconocer que el poder judicial, es en última instancia, el único habilitado para juzgar la validez de las normas dictadas por el órgano legislativo, y admitir, en consecuencia, la posibilidad de que el poder pueda residir y concentrarse en una sola sede". (Ingenio y Refinería San Martín del Tabacal de Salta c/ Salta" Fallos, 269:243 (1967).

A lo largo de esta exposición se ha ratificado el ejercicio monopólico del control de constitucionalidad por parte de la magistratura. Ello, sin embargo, no es óbice para impedir la posibilidad de que dicha actividad de control sea efectuada por un órgano de otra naturaleza, en tanto es inherente el ejercicio de su función de procurar el interés público el estar sometido al texto constitucional y procurar su supremacía y la dignidad de la persona como estandarte del estado constitucional de derecho.

Esto no obstante, ha sido rechazado por la mayoría de la doctrina nacional y los fallos jurisprudenciales clásicos, de tal manera que aunque bien se reconoce la posibilidad de que la Administración Pública haga ejercicio de funciones judiciales ello no implica que sus órganos puedan hacer ejercicio del control de constitucionalidad (Sammartino, Patricio 2007). En coincidencia se pronuncia la Procuración del Tesoro de la Nación (Dictámenes PTN 84:102; Dictamen 282/2004 - 250:41; Dictamen -/1983 - 165:119. 26 de Abril de 1983. En similar sentido (Dictámenes 67:189; 72:132; 136:400; etc.), Dictamen -/1985 -173:160. 15 de Mayo de 1985; Dict. 176:116; 192:144; 242:626).

Sin embargo, la tradicional doctrina que considera el control de constitucionalidad de las normas como acto de mayor gravedad institucional de nuestro estado a cargo del órgano judicial, se ve ampliada por una nueva tesitura, en tanto a la idea de presunción de legitimidad de los actos de gobierno, como derivación inmediata del principio de juricidad y legalidad que envuelve a todos los órganos que ejecutan la voluntad del estado. Atento ello, la función de la administración pública excede ya por mucho la conceptualización clásica que le imputada como única misión la de ejecutar las leyes, y someterse 
en todo su ejercicio al plexo normativo positivo imperante. Esta tradicional visión ha sido desbordada por el concepto mismo de interés público al que la administración esta llamada, en cuyo seno reside no sólo el cumplimiento y ejecución de normas como garantía para los administrados, sino que el concepto mismo de interés público ha mutado hoy hacia el sostenimiento de la vigencia plena de la constitución nacional y el bloque que esta integra:

"En este tipo de estado, el principio de juridicidad no solo se satisface mediante el sometimiento formal de la función administrativa a los procedimientos legales; aquél impera, además, el efectivo y concreto aseguramiento -para todos los miembros de la comunidad- de los bienes que asegura y protege la Constitución como fuente primera de juridicidad. El estado constitucional enfatiza la juridicidad por los valores (...) El principio de juricidad, en el estado constitucional, exige que el acto administrativo adecue su contenido y finalidad a las exigencias formales y materiales de la juricidad por los valores que inspira hoy la constitución reformada. " (Sammartino, Patricio 2007, p. 16).

\section{4.a- La potestad de no aplicación de normas presuntamente inconstitucionales antes del fallo Hooft.}

Tiempo antes incluso que la Corte se pronunciara a favor de la existencia de normas presuntamente inconstitucionales, se ha sostenido que la administración pública conserva la potestad de no aplicar leyes cuando están resultaren con vicios de manifiesta contradicción a la constitución nacional, pues ante un examen valorativo, mayor seria el perjuicio para la administración misma la aplicación de dicha norma que sufrir las críticas por no someter su actividad a la ley debida.

Tal fue incluso expresado por dictámenes de la Procuración del Tesoro de la Nación que parecían dispensar la ejecución de normas de dicha naturaleza (Dictámenes PTN 84:102, 189:140 y 192:144):

"(...) puede anticiparse una resistencia generalizada que se concretará en un número creciente de pleitos que, de no darse circunstancias muy especiales, permiten prever una suerte adversa para la Administración, con los consiguientes perjuicios para esta y para los administrados. Lo más ortodoxo es que el Presidente, ante esta situación, se dirija al Congreso auspiciando la derogación de las normas impugnadas y las circunstancias pueden aún justificar que, simultáneamente se instruya a los órganos de aplicación en el sentido de que, evitar los perjuicios consiguientes, se suspenda la aplicación de la ley" (Dictamen PTN 192:144, 1990).

En similar sentido, hacia el año 2002, la Procuración del Tesoro de la Nación resolvía que "la jerarquía de la Corte Suprema de Justicia de la Nación, el carácter definitivo de sus sentencias, la armonía que debe haber entre los distintos órganos estatales, y la necesidad de ahorrarle al Estado los gastos que se derivarían de acciones judiciales previsiblemente desfavorables, determina la conveniencia de que la Administración Pública se atenga a los criterios del máximo Tribunal en cuanto a la aplicación e interpretación del Derecho, aun cuando se opongan a los de la Procuración del Tesoro" (PTN 243:1 y 231:189).

Todo esto tiene por resultado debilitar la concepción clásica del principio de legalidad y juricidad al que está desde sus inicios sometida la administración pública, dando también lugar a la posibilidad, que luego se haría efectiva en el año 2003 con el fallo Hooft, de revertir el sentido del principio general de presunción de legalidad de las normas cuando estas evidenciaran vicios de importancia.

Esta posibilidad era simplemente tenida como una cuestión de mera economía procesal, evitando perjuicios económicos o un desgaste innecesario de recursos. Seria recién a 
través del caso Hooft que la reforma constitucional de 1994, la dignidad de la persona humana y la nueva perspectiva del interés público alcanzarían real vigencia.

\section{4.b- El deber de no aplicación de normas presuntamente inconstitucionales y el implí- cito control de constitucionalidad después del fallo Hooft.}

Llegamos finalmente a analizar la verdadera impronta que ha tenido para la administración pública y todo el sistema de control de constitucionalidad, la decisión de la Corte en el caso Hooft (2003), cuestión que luego sería continuada, como ya fue explicado por los fallos Gottschau (2006), Reyes Aguilera (2007) y Mantecón Valdez (2008), donde nuestro más alto tribunal termina de delinear la cuestión de las normas presuntamente inconstitucionales, con un mandato imperativo a los órganos de la administración pública, de llevar a cabo previo a expedirse, y siempre que se dieran los extremos necesarios, el denominado TEST DE HOOFT.

Como pudo verse oportunamente, el test de Hooft resume la mecánica debida por todos aquellos llamados a aplicar una norma en el caso concreto, cuya tarea consiste en verificar previo a ello, si dicha normativa lleva ínsita un agravio manifiesto y una total incoherencia con respecto a la constitución. En caso de ser ello afirmativo, la administración tiene no solo la potestad sino el deber de no aplicar dicha normativa por ser contraria a la dignidad de la persona y el bloque de constitucionalidad al que está llamado a respetar.

La CSJN ha consolidado así el principio que junto a la presunción de validez de las normas, de donde devenía la fuerza obligatoria de los actos estatales, coexisten en simultáneo, las normas presuntamente inconstitucionales.

Tenemos así, que antes de esta reforma, la presunción de constitucionalidad podía sólo ser retirada a través de una efectiva declaración del órgano judicial, quien decidiendo ante un caso concreto. Actualmente y en virtud de lo innovado por la CSJN, los distintos órganos del estado pueden por sí mismos llevar a cabo un contro/ de constitucionalidad y determinar que una ley o normativa particular está afectada, omitiendo en el caso concreto su aplicación, de manera tal que quien se entienda afectado por la no aplicación de estas norma presuntamente inconstitucional debe demostrar su constitucionalidad, es decir su coherencia con el texto magno.

Ello prueba la inversión de la carga probatoria, cual se encontraba antes sólo en cabeza de quien pretendía descalificar una norma. De allí tenemos pues que "así como la norma que se supone legítima está dotada por ello de fuerza obligatoria, la disposición normativa que no goza de esa suposición general de validez carece, en principio, de exigibilidad jurídica" (Sammartino, Patricio 2009, p. 82)

\section{Reflexiones finales}

La omisión del constituyente en la definición de reglas expresas sobre el sistema del control de constitucionalidad en Argentina ha traído consigo un proceso de auto atribución monopólica judicial, a partir de cuya labor jurisprudencial, el máximo tribunal del país definió las notas caracterizantes de lo que se ha resuelto denominar como sistema tradicional o clásico argentino.

Sin embargo, nuevos pronunciamientos de este órgano manifiestan un proceso de mutación sobre los límites y alcances del sistema de control tradicional, volviéndolos más elásticos y reconfigurando sus notas caracterizantes con vocación hacia un proceso de hibridación. 
En los términos expuestos, se transitó por una breve exposición del proceso de mutación al cual asiste el tradicional modelo de control de constitucionalidad federal argentino; ofreciendo desde allí una reflexión de aquellos pronunciamientos que habilitan el debate sobre las normas presuntamente inconstitucionales y el deber de los operadores de la administración pública de no aplicar dichas normas palmariamente viciadas en caso de encontrarse frente a estas.

Del análisis de dichos pronunciamientos se deriva una comparación entre los efectos del control de constitucionalidad -a cargo del órgano judicial- y el deber de no aplicar normas inconstitucionales por parte de la administración pública; en cuya consecuencia resulta la similitud de efectos entre ambos procesos, lo que nos conduce a reflexionar sobre la posibilidad de "habilitar/permitir" un control de constitucionalidad y una consecuente declaración de inconstitucionalidad por parte de otros poderes que no sean el judicial.

Así, reconociendo la similitud que en los efectos prácticos tanto la declaración de inconstitucionalidad por partes de los órganos judiciales, cuanto la no aplicación de normas presuntamente inconstitucionales por parte de la administración pública, traen aparejadas; en ambos casos el efecto inter partes implica en definitiva la no aplicación para el caso concreto de dicha norma encontrada contraria a la Constitución pero no la derogación general de dicha disposición.

Así las cosas, el órgano administrador lleva consigo el deber de no aplicar ciertas leyes por ser estas palmariamente inconstitucionales: "De consiguiente, las cláusulas constitucionales, legales, las disposiciones reglamentarias o los actos generales no normativos, que resulten portadores de presunción de inconstitucionalidad, no pueden sustentar jurídicamente un acto administrativo." Sammartino, Patricio 2009, p. 83), en tanto "Ciertamente, el indisoluble compromiso con el interés público y con los bienes jurídicos que por él se tutelan en el Estado constitucional, habilitan necesariamente a la Administración a examinar el antecedente de derecho aplicable (Art. 7o, inc. b), LNPA), debiendo en todos los casos dar preeminencia a la Constitución y sus valores por sobre el resto del ordenamiento infraconstitucional" (Sammartino, Patricio 2009, p. 88)

Así las cosas, la declaración de inconstitucionalidad de una norma por parte de un órgano judicial, produce la inaplicación de dicho instrumento entre la partes (efecto erga omnes), de la misma manera que lo hace la decisión de no aplicar una norma en un caso concreto la administración, siguiendo los nuevos lineamientos a partir de la doctrina Hooft: "la declaración de inconstitucionalidad en realidad constituye una declaración de inaplicabilidad" (Bianchi, Alberto 1990 P. 343).

La similitud entre ambos mecanismos, al parecer termina de fortalecerse reconociendo también que a partir del año 2011 la CIDH en instancias de pronunciarse en el caso Caso Gelman Vs. Uruguay. Fondo y Reparaciones -considerando 193- resolvió el deber en que se hayan todos los órganos de un estado parte "(...) de velar por que los efectos de las disposiciones de la Convención no se vean mermados por la aplicación de normas contrarias a su objeto y fin, por lo que los jueces y órganos vinculados a la administración de justicia en todos los niveles están en la obligación de ejercer ex officio un "control de convencionalidad" entre las normas internas y la Convención Americana, evidentemente en el marco de sus respectivas competencias y de las regulaciones procesales correspondientes (...)"; habilitando así un control de convencionalidad por parte de la administración pública. 
Restaría finalmente resolver si el ejercicio del control de convencionalidad lleva ínsito un proceso de control de constitucionalidad -lo que a todas luces resulta coherente-, y cuyo reconocimiento resolvería definitivamente la problemática expuesta en el presente trabajo; y admitiría formalmente una nueva modulación de un control de constitucionalidad mixto, de matices judiciales -por medio del cual se dirimen conflictos con fuerza de verdad legal a través de sentencias que gozan de inmutabilidad-, y administrativos -tendiente no sólo a examinar la constitucionalidad de las normas que debe aplicar como antecedente de derecho aplicable propio de la función administrativa, sino tendiente a garantir la supremacía de la constitución en cada intervención en paridad a la máxima misión de nuestra Suprema Corte.

BIBLIOGRAFÍA

- AMAYA, Jorge A. (2012). Control de constitucionalidad. Buenos Aires, Astrea.

- BADENI, Gregorio. (2012) Tratado de derecho constitucional. Buenos Aires, La Ley, (7ma edición).

- BAZÁN, Víctor. (2010). "En torno al Estado de derecho, la justicia constitucional y la tutela de los derechos fundamentales, con particular énfasis en América Latina". Anuario iberoamericano de justicia constitucional. Documento en línea: (https://dialnet.unirioja. es/revista/4240/A/2010) (10/05/2018)

- BIANCHI, Alberto B.

(2002). Control de constitucionalidad (Vol. 1) (2da. ed.). Buenos Aires, Abaco.

(1990). Control de Constitucionalidad. El proceso y la jurisdicción constitucionales. Buenos Aires, Abaco.

- BIDART CAMPOS, Germán. (1996). Tratado Elemental de Derecho Constitucional Argentino. Buenos Aires, EDIAR.

- DALLA VIA, Alberto R.

(1997). "La justicia constitucional en Argentina". Anuario Iberoamericano de Justicia Constitucional. Centro de Estudios Políticos y Constitucionales, Madrid. №1, 1997, Pp. 35-48. (2009) "Modelos, tribunales y sentencias constitucionales". La Ley, A, 1158.

- EL FEDERALISTA № 78 (1787). PUBLIO.

- ESTEVARENA, María F. (2012). "Las sentencias constitucionales y el control de constitucionalidad en Argentina. ¿Nuevo paradigma?”. Revista Jurídica UCES. Nº16, 119-128.

- FERNÁNDEZ SEGADO, F. (2005). "La justicia constitucional ante el siglo XXI: la progresiva convergencia de los sistemas americano y europeo - kelseniano". Pensamiento Constitucional, $N^{\circ} 11$. Documento en línea (http://revistas.pucp.edu.pe/index.php/pensamientoconstitucional/article/view/7678) (05/12/2018)

- FERREYRA, R. Gustavo. (2004). "La Corte Suprema de Justicia argentina y el control de constitucionalidad: vicisitudes y restos del papel institucional del tribunal”. En Cuadernos constitucionales de la Cátedra Fadrique Furió Ceriol, № 47, págs. 13-44. Documento en línea (https://dialnet.unirioja.es/descarga/articulo/1705658.pdf) (19/02/2019)

- GARCIA, José F. (2003). "El control de constitucionalidad en el federalista y los fundamentos de una sociedad libre”. Revista chilena de derecho, vol. 30 № 3, pp.491-514.

- HARO, Ricardo. (2003).Control de constitucionalidad. Buenos Aires, Zavalía. 
- HIGHTON DE NOLAZCO, Elena I., (2011). "Sistemas concentrado y difuso de control de constitucionalidad", Bogdandy, Armin von et al. (coords.), La justicia constitucional y su internacionalización. ¿̇Hacia un lus Constitutionale Commune en América Latina?”. T. I, México, UNAM, Instituto de Investigaciones Jurídicas-MaxPlank InstitutfürausländischesöffentlichesRecht and Völkerrecht-Instituto Iberoamericano de Derecho Constitucional, 2011. Documento en línea (https://archivos.juridicas.unam.mx/www/bjv/libros/6/2894/10.pdf) (20/02/2019)

- MILLER, J. GELLI, M. A. CAYUSO, S. (1992) Constitución y Poder Político. Jurisprudencia de la Corte Suprema y técnicas para su interpretación. Buenos Aires, Astrea.

- MILLER, JONATHAN. (2006) "Control judicial de constitucionalidad y estabilidad constitucional: Sociología del modelo estadounidense y su colapso en la Argentina". En Revista UDT.

- PEGORARO, Lucio. (2002). "La circulación, la recepción y la hibridación de los modelos de justicia constitucional”. Anuario iberoamericano de justicia constitucional, № 6 , pp. 393-416.

- SAGUES, Néstor P.

(2001). Teoría de la Constitución. Buenos Aires, Astrea.

(2004). "Desafíos de la jurisdicción constitucional en américa latina". Foro constitucional iberoamericano, №. 8, 2004.

(2006) "Las sentencias constitucionales exhortativas". Revista del Centro de Estudios Constitucionales, vol. 4, nro. 002, Centro de Estudios Constitucionales, Santiago de Chile. - SAMMARTINO, Patricio.

(2009). "La causa y el objeto del acto administrativo en el estado constitucional". Revista Ediciones Especiales Cuestiones de Acto Administrativo, Reglamento y otras fuentes del Derecho Administrativo.

(2007) La noción de Acto Administrativo en el estado constitucional. Bs. As, argentina. - VANOSSI, Jorge R. (2004). "La influencia de la Constitución de los Estados Unidos de Norteamérica en la Constitución de la República Argentina". En Visiones de una Constitución, Jorge A. Amaya (Director) Universidad de Ciencias Empresariales y Sociales, Buenos Aires. 